Article

\title{
Cultivation of Microalgae and Cyanobacteria: Effect of Operating Conditions on Growth and Biomass Composition
}

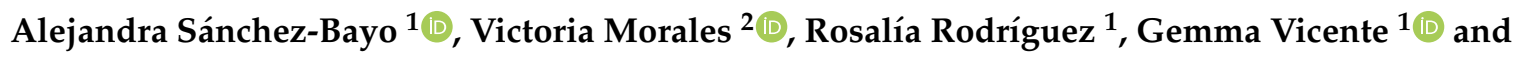 \\ Luis Fernando Bautista $2, * \mathbb{D}$ \\ 1 Department of Chemical, Energy and Mechanical Technology, ESCET, Universidad Rey Juan Carlos, \\ 28933 Móstoles, Madrid, Spain; alejandra.sanchezbayo@urjc.es (A.S.-B.); rosalia.rodriguez@urjc.es (R.R.); \\ gemma.vicente@urjc.es (G.V.) \\ 2 Department of Chemical and Environmental Technology, ESCET, Universidad Rey Juan Carlos, \\ 28933 Móstoles, Madrid, Spain; victoria.morales@urjc.es \\ * Correspondence: fernando.bautista@urjc.es; Tel.: +34-914888501
}

Academic Editors: Cristina González-Fernandez and Luisa Gouveia Received: 21 May 2020; Accepted: 15 June 2020; Published: 19 June 2020

\begin{abstract}
The purpose of this work is to define optimal growth conditions to maximise biomass for batch culture of the cyanobacterium Arthrospira maxima and the microalgae Chlorella vulgaris, Isochrysis galbana and Nannochloropsis gaditana. Thus, we study the effect of three variables on cell growth: i.e., inoculum:culture medium volume ratio (5:45, 10:40, 15:35 and 20:30 mL:mL), light:dark photoperiod $(8: 16,12: 12$ and 16:8 h) and type of culture medium, including both synthetic media (Guillard's F/2 and Walne's) and wastewaters. The results showed that the initial inoculum:culture medium volume ratio, within the range 5:45 to 20:30, did not affect the amount of biomass at the end of the growth (14 days), whereas high (18 h) or low $(6 \mathrm{~h})$ number of hours of daily light was important for cell growth. The contribution of nutrients from different culture media could increase the growth rate of the different species. A. maxima was favoured in seawater enriched with Guillard's $\mathrm{F} / 2$ as well as $C$. vulgaris and $N$. gaditana, but in freshwater medium. I. galbana had the greatest growth in the marine environment enriched with Walne's media. Nitrogen was the limiting nutrient for growth at the end of the exponential phase of growth for $C$. vulgaris and $N$. gaditana, while iron was for A. maxima and I. galbana. The growth in different synthetic culture media also determines the biochemical composition of each of the microalgae. All species demonstrated their capability to grow in effluents from a wastewater treatment plant and they efficiently consume nitrogen, especially the three microalga species.
\end{abstract}

Keywords: microalgae; cyanobacteria; biomass composition; culture optimisation; growth on wastewaters

\section{Introduction}

Microalgae, such as cyanobacteria and eukaryotic algae, are photoautotrophic microorganisms that use inexpensive and widely available natural resources, such as $\mathrm{CO}_{2}, \mathrm{H}_{2} \mathrm{O}$ and inorganic salts, to transform radiant energy into valuable products contained in the biomass. These photosynthetic microorganisms are among the most promising new sources of energy, since they are renewable and neutral with respect to $\mathrm{CO}_{2}$ emissions. The $\mathrm{CO}_{2}$ emitted after their use corresponds to that fixed from atmosphere by microalgae, so that no net $\mathrm{CO}_{2}$ emission is produced. Although the number of different algae and cyanobacteria species in nature is unknown, conservative estimations give values above 70,000 of which more than 40,000 have been published [1]. Because of this enormous number of species, we selected four different microorganisms with different compositions and behaviour in this work. 
Arthrospira maxima is a species belonging to the phylum of Cyanobacteria. These microorganisms are characterised for being able to perform photosynthesis and, traditionally, they have been grouped, alongside A. platensis, under the term Spirulina. Generally, they are arranged in multicellular filaments (50-500 $\mu \mathrm{m}$ long and diameters of 3-12 $\mu \mathrm{m}$ ) and have been found in tropical and subtropical waters of alkaline lakes containing high concentrations of carbonate, either in salt or freshwater [2]. The main advantage of these species is their high protein content, therefore they are used as food supplements. They also present great benefits to human health due to their antioxidant properties, their role as activator of cell regeneration, and their positive effect on kidney and memory problems [3].

Chlorella vulgaris is a small, spherical microalga with a size of $5-10 \mu \mathrm{m}$, belonging to the family of Chlorellaceae. It has high protein content and a balanced amino acid composition, which means that it is widely employed for human feeding. Different studies also show the possible mixotrophic behaviour of this specie [4].

Nannochloropsis gaditana is a microalga with a small size, around $3 \mu \mathrm{m}$. This microalga belongs to the Eustigmataceae family and the name of the genus, Nannochloropsis, derives from its small size. The species of this genus usually grow in salt water, although they have also been found in fresh and brackish waters [5]. The main use of this alga is the feeding of fish in aquaculture due to the high accumulation of pigments, such as xanthophylls, and of polyunsaturated fatty acids [6]. However, in recent years, it has been used for the production of biofuels, such as biodiesel, due to its lipid accumulation potential [7].

The microalga Isochrysis galbana belongs to the family of Isochrysidaceae. It is a unicellular species with a brownish colour and it has two flagella, with sizes within the range 3 to $5 \mu \mathrm{m}$. I. galbana is known to have good nutritional qualities, and it is used in aquaculture as feed in the early larval stages of molluscs, fishes and crustaceans. It is characterised by its capability to accumulate polyunsaturated fatty acids, particularly omega 3 such as eicosapentaenoic (EPA) and docosahexaenoic (DHA). Currently, it is being used to study the immuno-modulation properties of some of its components [8].

Recently, these microorganisms have been studied to produce different biofuels such as biodiesel [9], bioethanol [10], biogas [11] and biohydrogen [12]. In this context, the study of the cultivation stage is crucial to obtain a suitable microalgal biomass for the production of biofuels. Thus, the growth of photosynthetic microalgae and cyanobacteria is governed by several factors, such as temperature, $\mathrm{CO}_{2}$ supply, $\mathrm{pH}$, nutrients availability and light conditions, which should be optimised in photo-bioreactor systems for further industrial scale-up. Since light is the driving force of photosynthesis, it is the major abiotic parameter affecting cell metabolism. Photosynthetic organisms can be adapted to changes in light intensity and spectrum. Too much light may reduce microalgal productivity and have negative effects on the quality of biofuels, although photosynthetic organisms have evolved many strategies to protect themselves from photodamage. Light quality also has a substantial impact on cell metabolism [13], modulating the biomass composition of carbohydrates, lipids and proteins [14].

Photoperiod is a factor regulating cell division in asexual reproduction, which occurs during the light period, and it is accelerated under continuous illumination. Therefore, the photoperiod can be adjusted according to the objectives of the culture: a continuous lighting produces rapid growth, whilst a photoperiod, alternating hours of light and dark, like the solar photoperiod, maintains a normal and healthy growth. The short-term and long-term adaptations associated with balances in photosystem stoichiometry have been investigated in relation to the spectral characteristics of light [15].

It has been found that another key factor favouring microalga growth is the presence of micronutrients, such as vitamins, in the culture medium [16,17]. The axenic culture of microalgae demands a more stringent composition of nutrients in their cultivation medium. Therefore, special formulations of standard media such as Walne's [18] and Guillard's F/2 [19] media are normally used to produce microalga monoculture at the laboratory scale. The sufficient supplement of nutrients for microalga growth is a key step to produce a bulk quantity of high quality microalgal biomass. Microalgae can grow in polluted waters because the waters may contain some of the required nutrients. Therefore, municipal, industrial or agricultural wastewaters can be used as cultivation media while 
simultaneously act as a biological treatment to remove and recycle nitrogen and phosphorus from those streams [20-22].

In this work, we studied the effect of three key variables on the final maximum biomass growth of one cyanobacterium (A. maxima) and three microalgae (C. vulgaris, N. gaditana and I. galbana). First, we analysed the effect of the initial inoculum:culture medium volume ratio, the light photoperiod and the culture media composition for each microorganism. After studying the optimal culture conditions, the experiments were scaled-up to a larger volume $(12 \mathrm{~L})$ to proceed with the evaluation of the macromolecular and elemental composition of the microalgal biomass, measuring protein, carbohydrate and lipid content. Additionally, we studied the consumption of different nutrients and micronutrients during the growth and the results were evaluated in terms of dry weight and cell concentration fitting the results to Monod growth kinetics. With the aim to test growth and nutrients depletion in wastewaters, cultivation of microalgae and cyanobacteria was also carried out using water from different processes of a wastewater treatment plant.

\section{Results and Discussions}

\subsection{Analysis of Variables to Maximize the Biomass}

The inoculum:culture medium ratio was studied for all species at $25^{\circ} \mathrm{C}$ using synthetic seawater with Guillard's F/2 as a culture medium under 12:12 h light:dark photoperiod. As can be seen in Figure 1, there was no significant difference between the ratios studied at the stationary growth phase for each species. As cultures reach the end of the exponential phase, growth curves for different inoculum:culture medium ratios approach the same plateau value as observed for I. galbana cultivated in raceway ponds [8]. This may be due to the fact that biomass concentration was high enough to produce cell-shading.

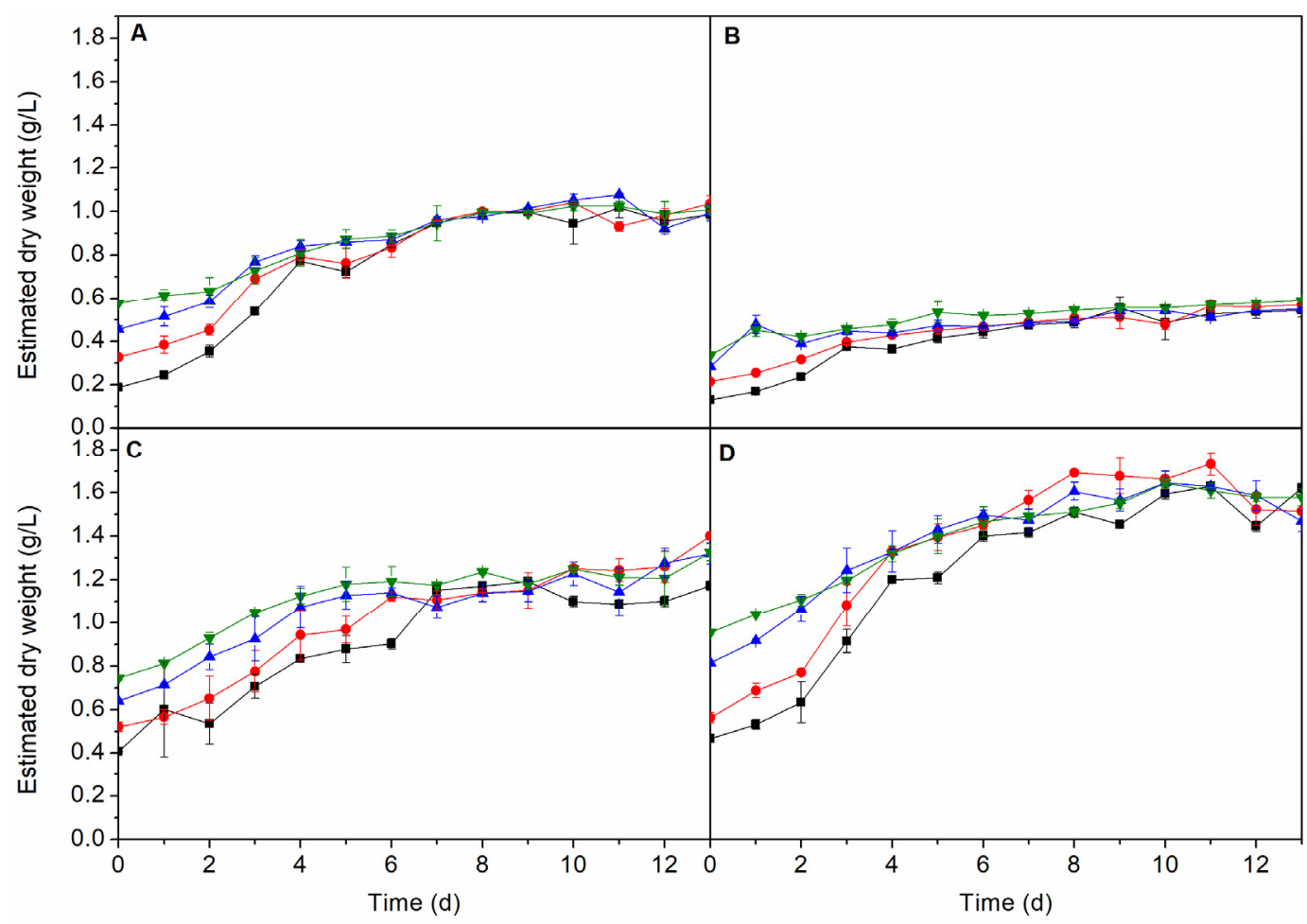

Figure 1. Growth of A. maxima (A), C. vulgaris (B), I. galbana (C) and N. gaditana (D) at different inoculum:culture medium ratio ( $\mathbf{\square}: 45, \bullet 10: 40, \wedge$ 15:35 and $\nabla$ 20:30) under 12:12 h light:dark photoperiod. 
Taking this into account, subsequent studies were performed using the lowest inoculum:culture medium ratio ( $5 \mathrm{~mL}$ inoculum: $45 \mathrm{~mL}$ medium), since a low inoculum concentration decreases the costs without affecting the cellular reproduction time.

Light is a key parameter for the growth of photosynthetic organisms to carry out their metabolic processes [23,24]. The light:dark cycle determines the stage of development of the alga, i.e., cell division occurs during the light phase while the dark phase is used to accumulate reserves [25]. It has been shown that carbohydrates are mainly accumulated after light exposures above $8 \mathrm{~h}$ and, in the case of lipids, when the light period is longer than $12 \mathrm{~h} \mathrm{[26].} \mathrm{However,} \mathrm{other} \mathrm{studies} \mathrm{have} \mathrm{shown} \mathrm{that} \mathrm{the}$ accumulation of lipids not only depends on the light phase, but also on other variables [27]. The results showed how the growth of A. maxima, C. vulgaris and N. gaditana depends largely on the number of hours of light exposure.

The light:dark photoperiod was studied at three different values (Figure 2). The two photoperiods with a larger number of light hours (18:6 and 12:12) increased production of biomass with respect to the 6:18 photoperiod for A. maxima, C. vulgaris and N. gaditana. In the case of A. maxima, the amount of dry weight reached a maximum of $0.95 \pm 0.03 \mathrm{~g} / \mathrm{L}$ after eight days, regardless of the light cycle used (18:6 and 12:12) while the biomass concentration for the 6:18 light:dark photoperiod was significantly lower $(0.54 \pm 0.09 \mathrm{~g} / \mathrm{L}, p$-value $>0.05)$. However, for that cyanobacteria, there is a clear difference between the longest light cycle (18:6) and the shortest (6:18) where a long lag phase is observed in the latter. To a lesser extent, a similar behaviour was measured for $N$. gaditana, where an average biomass concentration of $1.5 \pm 0.1 \mathrm{~g} / \mathrm{L}$ was reached after eight days for 18:6 and 12:12 photoperiods, higher than $0.94 \pm 0.05 \mathrm{~g} / \mathrm{L}$ ( $p$-value $>0.05)$, the value reached at that time when the $6: 18$ photoperiod was used. However, at the end of the cultivation (13 days) the average biomass concentration was $1.7 \pm 0.1 \mathrm{~g} / \mathrm{L}$, not showing statistical differences between all three photoperiods. In the case of $C$. vulgaris, the shortest light cycle (6:18) did not show the exponential growth phase and longer exposures to light resulted in biomass concentration of approximately $0.5 \pm 0.1 \mathrm{~g} / \mathrm{L}$ at the end of the cultivation experiment. Growth of I. galbana seems to be somewhat insensitive to the light:dark photoperiod because, in all cycles studied, the stationary phase was reached after seven days attaining a dry weight of $1.2 \pm 0.1 \mathrm{~g} / \mathrm{L}$ independently of the photoperiod. 


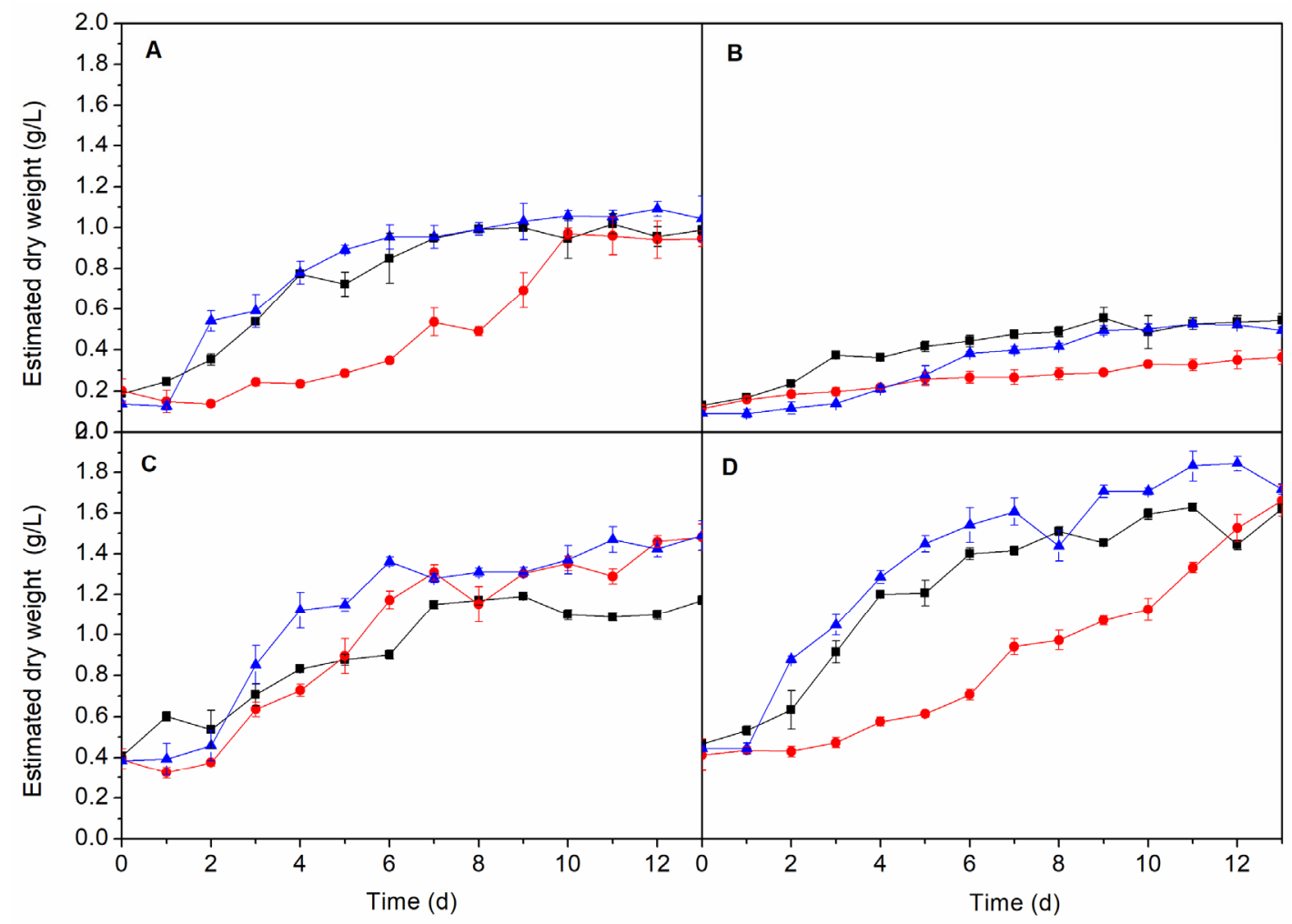

Figure 2. Growth of A. maxima (A), C. vulgaris (B), I. galbana (C) and N. gaditana (D) at different light:dark photoperiod $(\bullet 6: 18, \boldsymbol{\square} 12: 12$ and $\Delta$ 18:6 h).

Therefore, with the objective of achieving the optimum conditions of culture for each species, a 12:12 photoperiod was selected for further studies, since it provides the larger amount of biomass in some cases and it is closer to the natural light-dark cycle. Therefore, by using the photoperiod at the industrial scale, the artificial supplementation of energy in the form of light is not necessary to reach the higher biomass concentration achieved in the laboratory.

Three synthetic marine culture media were tested for growing all four species (Table 1 and Table S1): Guillard's F/2 (MC1), plain synthetic seawater (MC2) and Walne's (MC3). Additionally, A. maxima, C. vulgaris and N. gaditana were grown in two freshwater culture media: Guillard's F/2 (MC4) and Walne's (MC5). All the experiments were conducted with an inoculum:culture medium ratio of 5:45 and a photoperiod of 12:12 h previously selected for optimal conditions.

Table 1. Cultivation media ${ }^{1}$.

\begin{tabular}{|c|c|c|}
\hline Identification & Type & Description \\
\hline MC1 & Synthetic seawater & Guillard's F/2 medium \\
\hline MC2 & Synthetic seawater & $\begin{array}{l}\text { Distilled water with } 33 \mathrm{~g} / \mathrm{L} \text { of marine } \\
\text { salt with } 50 \mathrm{mg} / \mathrm{L} \mathrm{Mg} \text { and } 400 \mathrm{mg} / \mathrm{L} \mathrm{Ca} \text {. }\end{array}$ \\
\hline MC3 & Synthetic seawater & Walne's medium \\
\hline MC4 & Freshwater & Guillard's F/2 medium \\
\hline MC5 & Freshwater & Walne's medium \\
\hline AD1 & Wastewater & After primary decanter \\
\hline AD2 & Wastewater & After biological treatment \\
\hline AD3 & Wastewater & After secondary decanter \\
\hline
\end{tabular}

The results obtained with the synthetic marine water (MC2) for all microalgae (Figure 3) exhibit a very limited growth when compared to the other media, since MC2 is the only medium that was not enriched with vitamins and oligoelements. For A. maxima, the results showed that MC1 was the best 
culture medium ( $p$-value $<0.05$ ). Under these conditions, cell growth yielded $0.99 \pm 0.02 \mathrm{~g} / \mathrm{L}$ of dry biomass. For I. galbana, MC3 produced even higher biomass production ( $p$-value $<0.05)$, reaching values of $1.50 \pm 0.08 \mathrm{~g} / \mathrm{L}$ of dry weight. The microalga growing in freshwater, i.e., C. vulgaris and $N$. gaditana, showed the best performance when cultured in MC4 medium, with biomass concentrations of $0.52 \pm 0.03$ and $2.16 \pm 0.05 \mathrm{~g} / \mathrm{L}$, respectively, although MC1 produced similar growth on $C$. vulgaris $(0.54 \pm 0.03 \mathrm{~g} / \mathrm{L}, p$-value $>0.05)$.

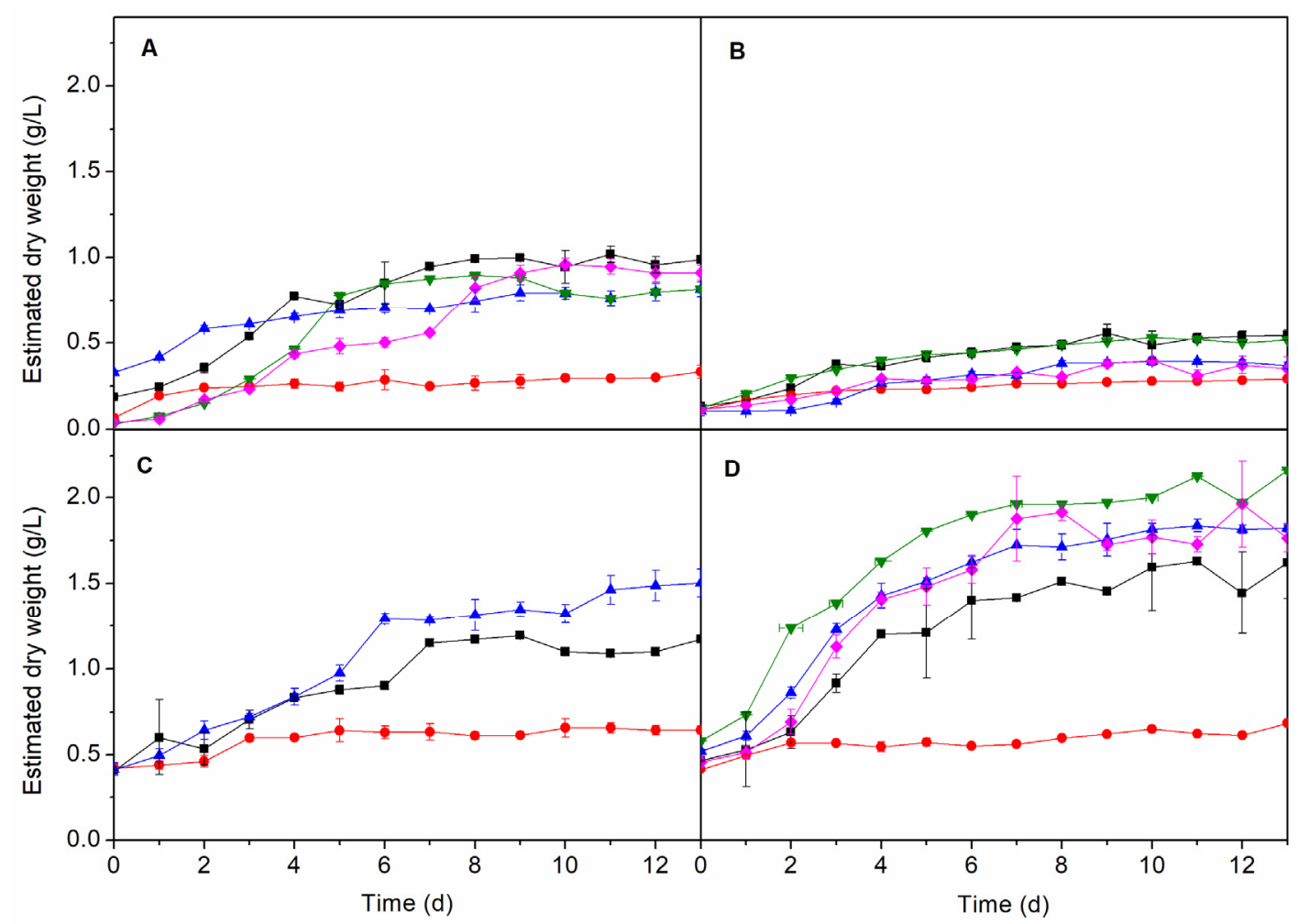

Figure 3. Growth of A. maxima (A), C. vulgaris (B), I. galbana (C) and N. gaditana (D) with different culture media ( $\mathbf{M C} 1, \bullet \mathrm{MC} 2, \triangle \mathrm{MC} 3, \mathbf{\mathrm { MC }} 4$ and $\triangleright \mathrm{MC5})$. Conditions for all cultivations: inoculum:culture medium ratio of 5:45 and a photoperiod of 12:12 h.

From the above results, the optimal conditions for the growth of A. maxima and I. galbana are seawater enriched with Guillard's F/2 (MC1) and Walne's (MC3) media, respectively. On the other hand, N. gaditana and C. vulgaris showed their best performance in freshwater enriched with Guillard's $\mathrm{F} / 2$ medium (MC4).

\subsection{Nutrients Uptake}

Cultivation media MC1 (for A. maxima) and MC4 (for N. gaditana and C. vulgaris) had an initial nitrate concentration of $134 \mathrm{mg} / \mathrm{L}$ and MC3 (for I. galbana) started with $100 \mathrm{mg} / \mathrm{L}$ of nitrate. Figure 4 shows nitrate removal by each microalga as growth progresses with time in cultivations performed under the optimal conditions selected previously. The results showed high nitrate removal $(>97 \%)$ for C. vulgaris $(97.4 \pm 0.9 \%)$ and $N$. gaditana $(97.4 \pm 0.5 \%)$ by the end of the experiments. In the case of the cultivation performed with I. galbana, nitrate was depleted in a $93.9 \pm 0.3 \%$ by day six and for A. maxima, the maximum nitrate removal reached $90.3 \pm 0.5 \%$ at day 10 . The above values agree with other results found in the literature [28,29]. In the individually optimised culture conditions, C. vulgaris showed higher nitrogen requirements for growth because that species consumed most nitrogen to yield the lowest $(p$-value $<0.05)$ biomass concentration $(0.52 \pm 0.03 \mathrm{~g} / \mathrm{L})$ at the end of the experiment (Figure $4 \mathrm{~B}$ ) as evidenced by its lower $(p$-value $<0.05)$ biomass yield value $\left(Y_{X / S}=3.0 \pm 0.2 \mathrm{~g} / \mathrm{g}\right.$, Table 2$)$. Meanwhile, $N$. gaditana was able to grow up to $2.15 \pm 0.07 \mathrm{~g} / \mathrm{L}$ (Figure $4 \mathrm{D}$ ), more than two-fold to that 
observed for A. maxima, $0.99 \pm 0.03 \mathrm{mg} / \mathrm{L}$ (Figure 4A) showing similar nitrogen removal in both cases. Therefore, nitrogen is an essential nutrient acting as a possible limiting substrate in the cultivation. The nitrogen/phosphorus ratio for the used nutrient medium based on Guillard's F/2 and Walne's were 44.4 and 7.5, respectively, which correspond to common values reported in literature where nitrogen proved to be the limiting nutrient [30].

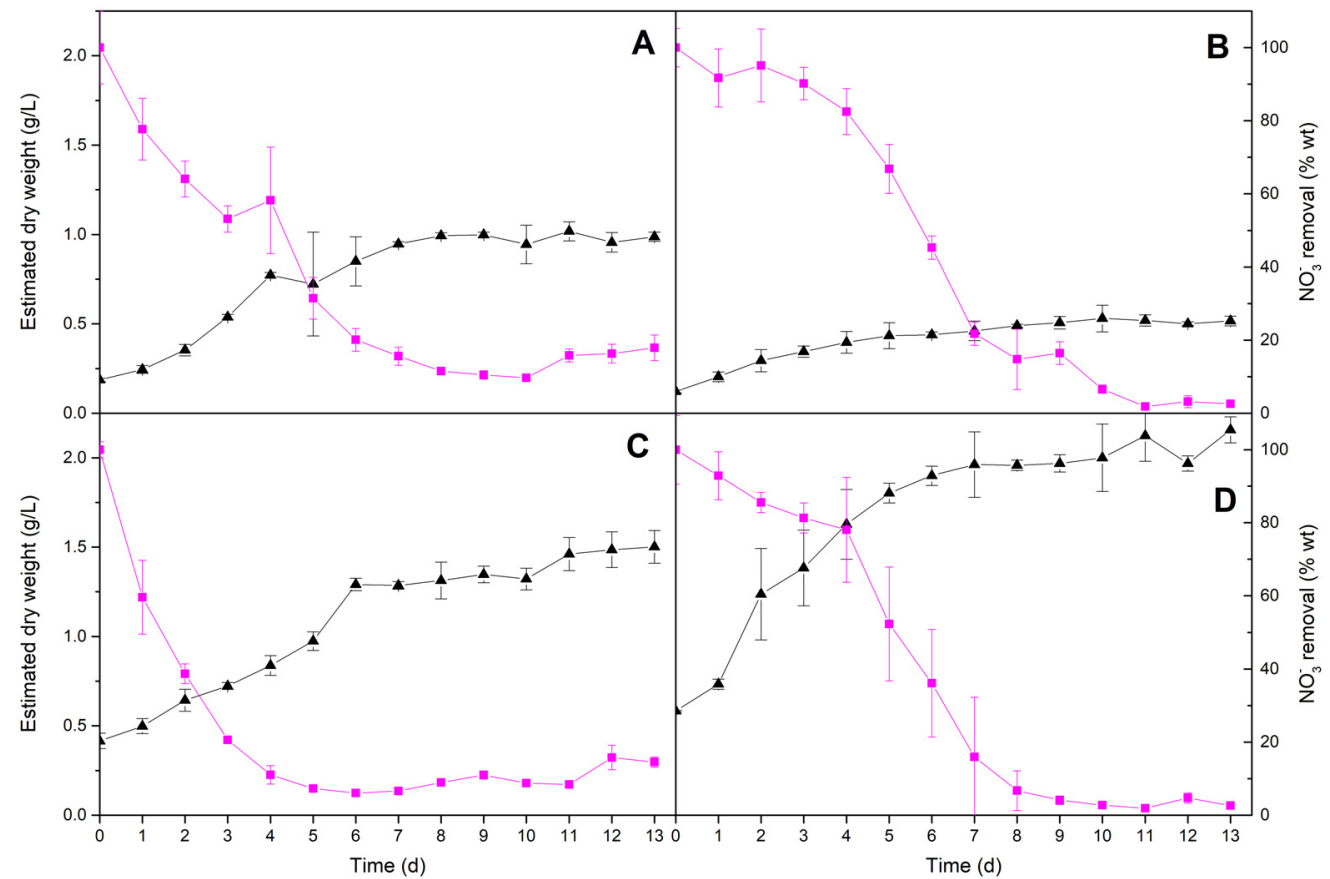

Figure 4. Biomass concentration (dry basis) $(\boldsymbol{\Lambda})$ and nitrate concentration in the culture medium $(\square)$ of A. maxima in MC1 (A), C. vulgaris in MC4 (B), I. galbana in MC3 (C) and N. gaditana in MC4 (D). Conditions for all cultivations: inoculum:culture medium ratio of 5:45 and a photoperiod of 12:12 h.

Table 2. Monod's kinetic parameters.

\begin{tabular}{cccc}
\hline Species & $\mu_{\max }\left(\mathbf{d}^{-\mathbf{1}}\right)^{\mathbf{1}}$ & $\mathbf{K}_{\mathbf{S}}(\mathbf{m g} / \mathbf{L})^{\mathbf{2}}$ & $\mathbf{Y}_{\mathbf{X} / \mathbf{S}}(\mathrm{g} / \mathbf{g})^{\mathbf{3}}$ \\
\hline A. maxima & $0.202 \pm 0.006$ & $1.7 \pm 0.8$ & $6.7 \pm 0.2$ \\
C. vulgaris & $0.27 \pm 0.02$ & $38 \pm 10$ & $3.0 \pm 0.2$ \\
I. galbana & $0.145 \pm 0.003$ & $11.8 \pm 0.7$ & $12 \pm 1$ \\
N. gaditana & $0.181 \pm 0.008$ & $4 \pm 2$ & $12.0 \pm 0.6$ \\
\hline
\end{tabular}

${ }^{1}$ Maximum specific growth rate, ${ }^{2}$ Half-saturation constant, ${ }^{3}$ Biomass yield on nitrate. Common conditions for all cultivations: inoculum:culture medium ratio of 5:45 and a photoperiod of 12:12 h. Growth media: A. maxima (MC1), C. vulgaris (MC4), I. galbana (MC3) and N. gaditana (MC4).

From the exponential growth phase and nitrate consumption (Figure 4), the Monod parameters ( $\mu_{\max }$ and $K_{S}$ ) were calculated for all four species (Table 2) using Equations (1) and (2) (see Section 3.5. Growth kinetics).

The growth kinetic parameters can be notably affected by culture conditions, including ambient conditions and type and concentration of nutrients [31]. Although the values of the maximum specific growth rate in similar experimental conditions have not been reported for $A$. maxima, the value achieved in this work $\left(\mu_{\max }=0.202 \pm 0.006 \mathrm{~d}^{-1}\right)$ was higher $(p$-value $<0.05)$ than that found for other Arthrospira species (A. platensis) cultivated in batch mode using a medium with similar salinity $\left(\mu_{\max }=0.182 \pm 0.007 \mathrm{~d}^{-1}\right)$ [32]. For $C$. vulgaris, the value of $\mu_{\max }=0.27 \pm 0.02 \mathrm{~d}^{-1}$ was within the range $\left(0.25-0.32 \mathrm{~d}^{-1}\right)$ of other studies where this species was cultured in wastewaters supplemented with ammonium [11]. Similar values were measured for the microalgae I. galbana $\left(\mu_{\max }=0.145 \pm 0.003 \mathrm{~d}^{-1}\right)$ and $N$. gaditana $\left(\mu_{\max }=0.181 \pm 0.008 \mathrm{~d}^{-1}\right)$. With respect to the half-saturation parameter, the $\mathrm{K}_{\mathrm{s}}$ values 
showed a high affinity of each microorganism for nitrate, especially in the case of $A$. maxima and $N$. gaditana, whose low values were $1.7 \pm 0.8 \mathrm{mg} / \mathrm{L}$ and $4 \pm 2 \mathrm{mg} / \mathrm{L}$, respectively. This means that both species can be very efficient at depleting nitrates from culture media up to very low concentrations. For C. vulgaris $\left(\mathrm{K}_{\mathrm{S}}=38 \pm 9 \mathrm{mg} / \mathrm{L}\right)$ and $I$. galbana $\left(\mathrm{K}_{\mathrm{s}}=11.8 \pm 0.7 \mathrm{mg} / \mathrm{L}\right)$, the half-saturation constants, although higher than those measured for the other two studied species, are low enough to achieve a good nitrate removal efficiency, showing similar values than those reported in the literature for nitrate as limiting nutrient [21].

To evaluate other essential nutrients, the consumption of oligoelements was monitored in the culture media for seven days (Figure 5). All microalgae consumed all iron present in the culture media in a few days. I. galbana needed a larger amount of iron (70 mg/L) compared with the rest of the species (approximately $20 \mathrm{mg} / \mathrm{L}$ ). In the case of microalgae cultivated in freshwater, a notable consumption of iron was observed, with $28 \%$ and $12 \%$ of iron remaining unused in the case C. vulgaris and N. gaditana, respectively. However, these microalgae have a total consumption of nitrate leaving some iron present in the culture media. Marine microalgae completely consumed copper, whereas in the case of freshwater species it was not significantly depleted. The presence of boron in marine species also decreased.

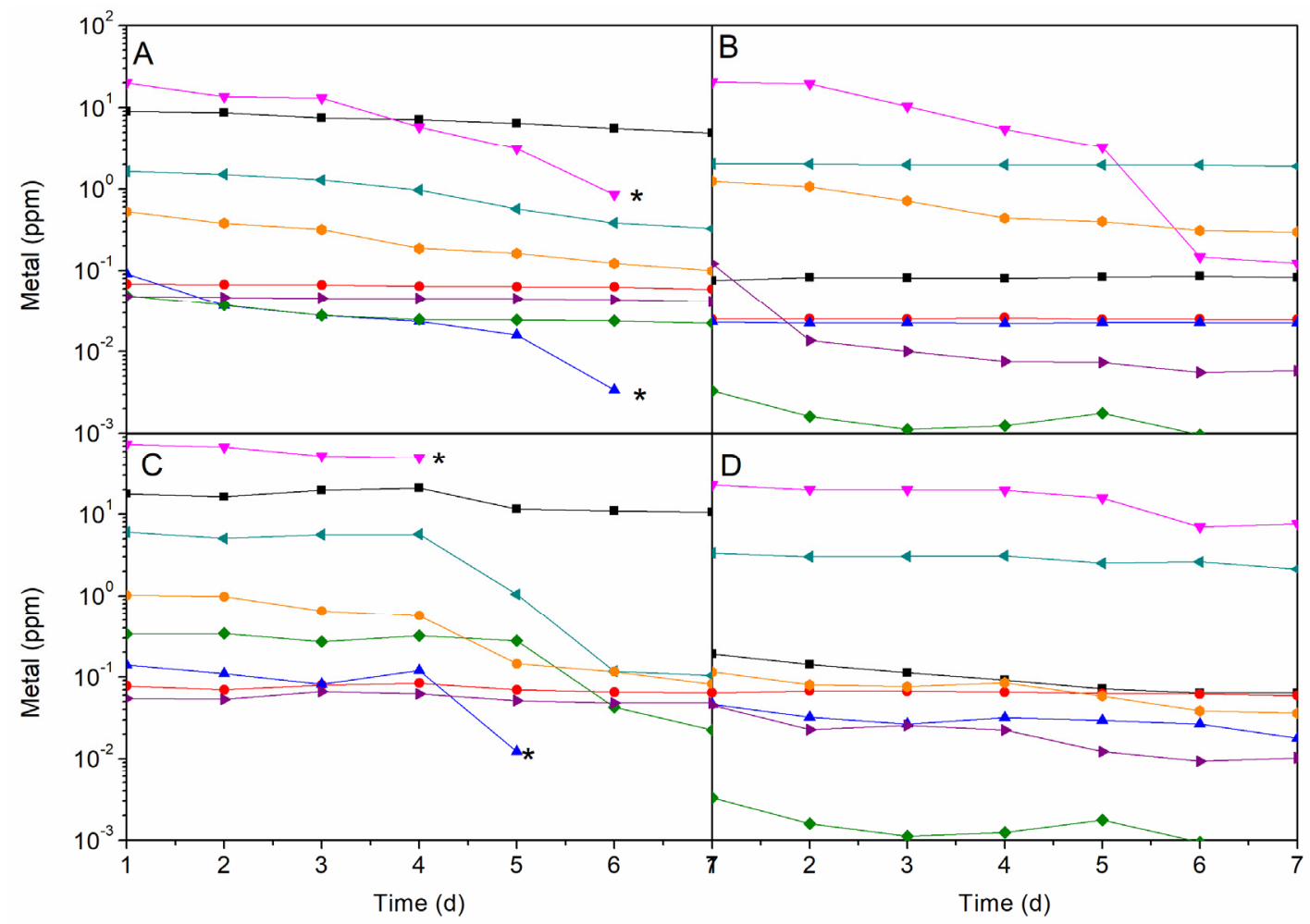

Figure 5. Trace element concentration in the culture media during optimum growth of $A$. maxima in MC1 (A), C. vulgaris in MC4 (B), I. galbana MC3 (C) and N. gaditana in MC4 (D) (घ B, • Co, $\Delta$ Cu, $\nabla \mathrm{Fe}$, $\checkmark \mathrm{Mn}, \triangleleft \mathrm{Mo}, \triangleright \mathrm{P}, \bullet \mathrm{Zn},{ }^{*}$ completely consumed). Conditions for all cultivations: inoculum:culture medium ratio of 5:45 and a photoperiod of 12:12 h.

\subsection{Biomass Composition}

At the optimum conditions selected for each species, growth was studied during 14 days in batch cultures, monitoring $\mathrm{pH}$, biomass composition and nutrient uptake. The $\mathrm{pH}$ is determinant for microalgal growth and all initial culture media had a $\mathrm{pH}$ value of 7.5. During cultivation, all species increased their $\mathrm{pH}$ over time, but this increase was mainly concentrated in the first part of the exponential phase (data not shown). The values reached for $A$. maxima were greater than 8 , a value that corresponds to the optimal values of the species of the genus Arthrospira, which generally develop 
in alkaline media [33]. The culture carried out with C. vulgaris in fresh culture medium generated a $\mathrm{pH}$ increase from the initial one of 7.5 to 9 during the first $48 \mathrm{~h}$. This is associated with the fast $\mathrm{CO}_{2}$ consumption driving the $\mathrm{pH}$ towards alkaline values. This microalga is grown in a wider $\mathrm{pH}$ range than the rest of the microalgae (6.3-9) [34]. N. gaditana is a species capable of developing at high $\mathrm{pH}$ values, around 8-10. The values obtained along the growth, around 8.5, were similar to those found in the literature $[35,36]$, confirming that the medium used provided a $\mathrm{pH}$ environment suitable for growth. In the case of I. galbana, $\mathrm{pH}$ values obtained were slightly higher than the rest of the species, being around $\mathrm{pH} 9$ [37].

The final $\mathrm{pH}$ was within the range 8-9 in all experiments, consistent with the values found in the literature [35], confirming that the media used provide a suitable $\mathrm{pH}$ environment for growth. The cultivation under extreme $\mathrm{pH}$ conditions, both acidic and basic, could allow for the use of certain wastewater for the growth of the four species studied [38].

The major building blocks of biomass from microalgae and cyanobacteria are proteins, carbohydrates and lipids, which were analysed until the end of the exponential phase of growth (first seven days of the trial). Figure 6 shows the monitoring of the biochemical composition during microbial growth at the optimum conditions selected for each species so far.

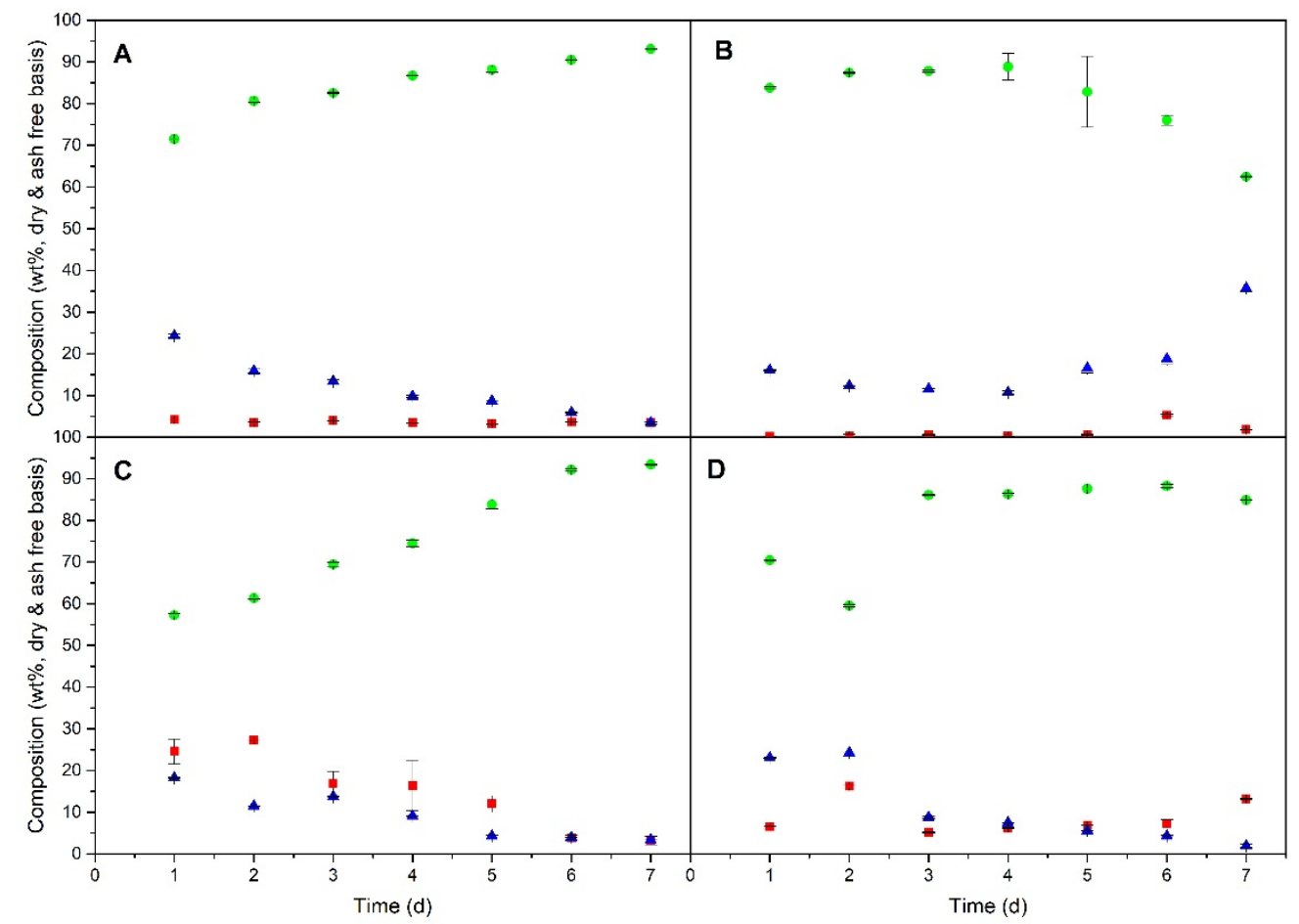

Figure 6. Time series of biomass composition (wt \%, dry and ash free basis) of: $\boldsymbol{\|}$ lipids, • proteins and $\Delta$ carbohydrates) for A. maxima in MC1 (A), C. vulgaris in MC4 (B), I. galbana in MC3 (C) and N. gaditana in MC4 (D). Conditions for all cultivations: inoculum:culture medium ratio of 5:45 and a photoperiod of $12: 12 \mathrm{~h}$.

Protein content increased during the exponential growth phase for A. maxima (Figure 6A) and I. galbana (Figure 6C), reaching values of $93.1 \pm 0.1 \%$ and $93.4 \pm 0.1 \%$, respectively, in line with previous studies [39]. However, the accumulation of proteins attained a maximum before the exponential phase ended for C. vulgaris (Figure 6B) and N. gaditana (Figure 6D). The protein concentration started to decline after four days in C. vulgaris. The protein content reached by I. galbana (93.4 $\pm 0.1 \%)$ was higher than that reported in Guillard's F/2 under continuous irradiance (45.31\%) [40]. This highlights the effect of the photoperiod on the composition of cell biomass. Of all protein content, soluble proteins were a small fraction of around 1-3\%, following a similar trend to that observed for total protein accumulation (data not shown). 
Carbohydrates in A. maxima (Figure 6A), I. galbana (Figure 6C) and N. gaditana (Figure 6D) showed decreasing values, from $15-25 \%$ to around $2-4 \%$, as growth progressed. This tendency is in agreement with other results shown in the literature [40-42]. However, carbohydrate content in C. vulgaris (Figure 6B) was approximately constant during the exponential phase, with values ranging from $10-18 \%$. Other studies [41], where low-nitrate modified Zarrouk's medium [43] was used, described higher carbohydrate accumulation in spirulina species than those reached by A. maxima in the present work. This higher amount of carbohydrates can be explained by the larger nitrate limitation and the greater availability of carbon due to the presence of $\mathrm{HCO}_{3}{ }^{-}$in Zarrouk's medium [44]. Most carbohydrates are not soluble and, thus, must be complex since carbohydrates mainly form cell walls as cellulose-like polymers and chitin-like glycans [45]. The lipid content during the first few days of cultivation (Figure 6) was lower than the values usually reported as the maximum lipid concentration for these species because the synthesis and accumulation of lipids in microalgae and cyanobacteria increases at the end of the exponential growth phase, when nitrogen starvation takes place (see, for example, [46-48]).

To contribute to a deeper understanding of biomass composition, elemental analysis was also performed during the lag and the exponential phases of growth of all four species. Therefore, the amounts ( $w \mathrm{t} \%$, dry basis) of carbon, hydrogen, nitrogen, sulfur and oxygen were determined (Tables S6 and S5). The carbon contents were high (20-53\%) and the nitrogen and hydrogen contents were minor as expected $(2-6.75 \%$ and $4-8 \%$, respectively). However, sulfur content was low $(<3.5 \%)$ and corresponds to sulfur amino acids (methionine and cysteine) in proteins.

One of the most important elements of study in the case of microalgae is the presence of nitrogen. Nitrogen is mainly contained in proteins and, to a lesser extent, in glycolipids from the cell walls and membranes, amino acids and sphingolipids. The nitrogen content was, in general, low (2-6\%), showing the lowest values in the case of A. maxima and I. galbana. This can be associated with lower protein content in these biomasses. As a result of the elemental analysis (see Tables S2-S5), the following average molecular formulae, in the exponential phase, were obtained for each species: $\mathrm{CH}_{1.93} \mathrm{O}_{1.61} \mathrm{~N}_{0.11} \mathrm{~S}_{0.02}$ (A. maxima), $\mathrm{CH}_{1.71} \mathrm{O}_{0.79} \mathrm{~N}_{0.07} \mathrm{~S}_{0.01}$ (C. vulgaris), $\mathrm{CH}_{2.73} \mathrm{O}_{1.09} \mathrm{~N}_{0.09} \mathrm{~S}_{0.04}$ (I. galbana) and $\mathrm{CH}_{1.61} \mathrm{O}_{0.60} \mathrm{~N}_{0.12} \mathrm{~S}_{0.01}$ (N. gaditana).

\subsection{Growth in Wastewaters}

All microalgae and cyanobacterium studied were able to grow in wastewaters (Table 1) maintaining the inoculum:culture medium ratio of 5:45 and a light photoperiod of 12:12, obtaining similar biomass production in the three non-sterilised wastewater samples (AD1, AD2 and AD3) (Figure 7). The above-four species were capable of developing in non-specific media as long as they had a certain content of salt in the culture medium that promoted metabolic development. This is due to the metals present in wastewater that serve as essential trace elements for the development of these species.

To evaluate the consumption of nutrients from wastewater, the analysis of the cultures performed in AD2 was carried out (see Figure S1), because the growth curves were similar in media AD1, AD2 and AD3. Generally, most of the nitrogen originating from sewage water is in the form of ammonium, nitrite or nitrates [49]. Initially, it is usually found that ammonium is converted into nitrite and then nitrate after a conventional biological treatment in the presence of nitrifying bacteria in a period of $24 \mathrm{~h}$, or it can be consumed in the form of ammonium [50-52]. Once the nitrogen is in the form of nitrate, it can be uptaken by the microalgae to proceed to the bioremediation of the water [53]. The nitrate content of the water sample at the outlet of the separator after the biological treatment (AD2) was $6.9 \mathrm{ppm}$ (Table S6). This low level of nitrate concentration may be due to the fact that in the biological separator certain bacteria were fed by this nutrient. The results showed a significant decrease of nitrates with microalgae $C$. vulgaris, I. galbana and $N$. gaditana up to $1-2 \mathrm{ppm}$, thus consuming $70-80 \%$ of the total. On the contrary, in the case of cyanobacterium, A. maxima only reached a consumption of about $30 \%$. This low nitrate depletion efficiency may be due to the need of a photoperiod with more light hours to increase the assimilation or the lack of phosphorus in the culture medium $[54,55]$. 


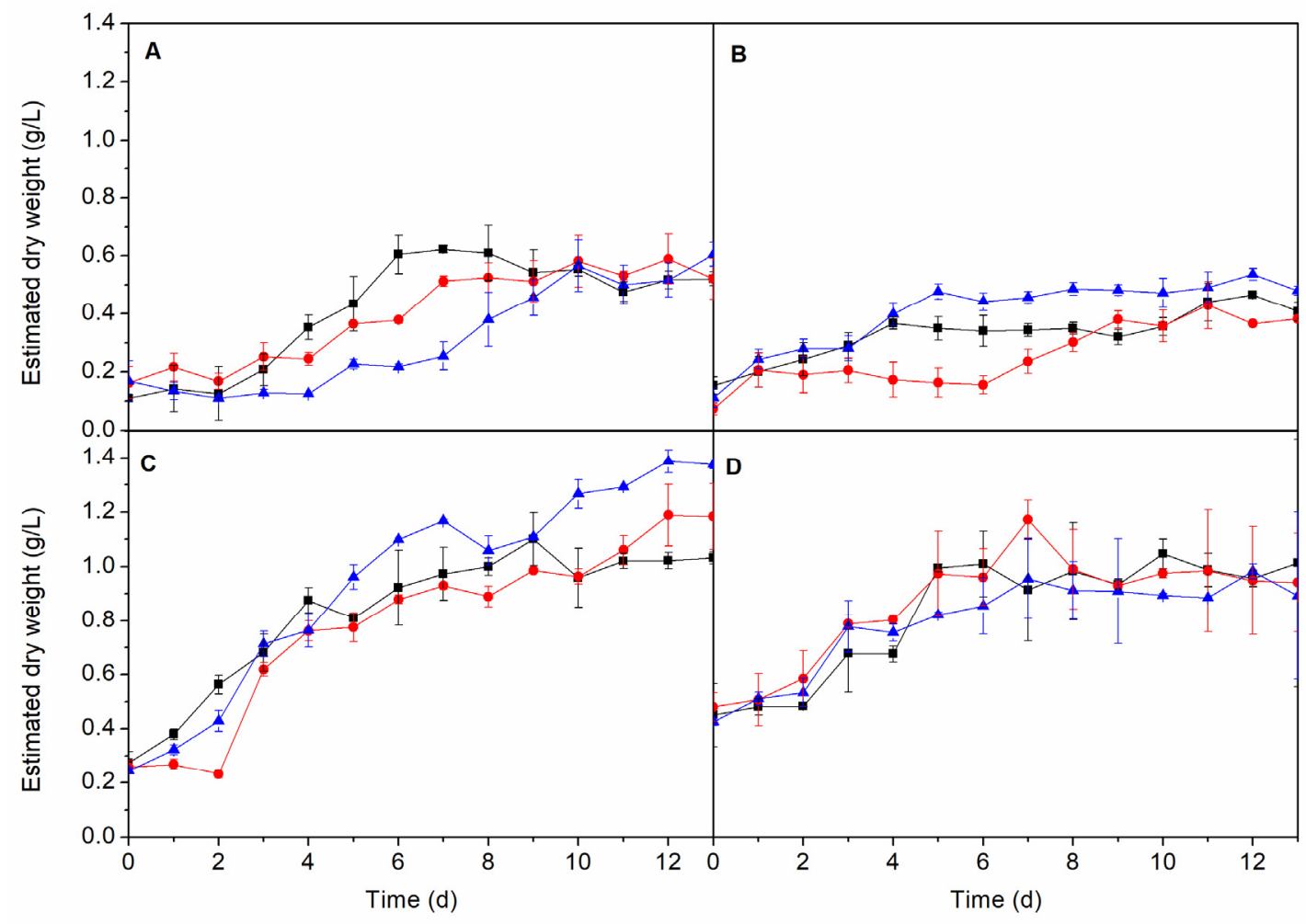

Figure 7. Growth of A. maxima (A), C. vulgaris (B), I. galbana (C) and N. gaditana (D) with different wastewater ( AD1, $\bullet \mathrm{AD} 2, \triangle \mathrm{AD} 3)$. Conditions for all cultivations: inoculum:culture medium ratio of $5: 45$ and a photoperiod of $12: 12 \mathrm{~h}$.

Despite the low concentration of nitrates in the culture medium, their low uptake can be caused by another limiting nutrient. There is a clear decrease in phosphorus in the culture medium $(>90 \%)$, for A. maxima and I. galbana while the rest of the elements present in the medium were consumed to a lesser extent (Table S7). This may be due to the fact that these metals are needed in very low amounts for the metabolic development of these species. All this seems to indicate that in these wastewaters, both nitrates and phosphorus, as well as the light photoperiod, must keep an optimum ratio to achieve a complete depletion of both nutrients [56,57].

\section{Materials and Methods}

\subsection{Microorganism}

Arthrospira maxima (SAG 49.88), Chlorella vulgaris (SAG 211.11-b), Isochrysis galbana (SAG 13.92) and Nannochloropsis gaditana (SAG 2.99) strains were obtained from the SAG Culture Collection of Algae (University of Gottingen, Gottingen, Germany).

\subsection{Chemicals}

Standards D-glucose ( $>99.5 \%$ purity) and sulfanilic acid ( $>99 \%$ purity) were purchased from Sigma-Aldrich (Saint Louis, MO, USA), sodium nitrate ( $>99 \%$ purity) from Scharlab (Barcelona, Spain) and bovine serum albumin (Quick Start BSA) from Bio-Rad Laboratories (Hercules, CA, USA). All other chemicals used were reagent grade: ethylenedinitrilotetraacetic acid disodium salt, phenylmethylsulfonyl fluoride, Triton-X100, dinitrosalicylic acid, sodium potassium tartrate tetrahydrate and methanol were supplied by Sigma-Aldrich and chloroform, sodium hydroxide, 98\% sulfuric acid and $48 \%$ hydrofluoric acid were purchased from Sharlab. 


\subsection{Growth Experiments}

Microalgae cultivations were carried out in $50 \mathrm{~mL}$ batch mini-photobioreactors where atmospheric air was continuously bubbling and in-line sterilised through a $0.45 \mu \mathrm{m}$ membrane filter. Air flow was provided only during light periods at a rate of $1.75 \mathrm{~L} / \mathrm{min}$. The inoculum:culture medium volume ratio used in this work were 5:45, 10:40, 15:45 and 20:30 mL:mL in order to assess whether a larger number of initial cells affects the growth rate and total biomass production at the end of the experiment or not. These ratios were chosen based on previous studies $[16,39,58-60]$. We tested three different light:dark photoperiods, i.e., $6: 18 \mathrm{~h}, 12: 12 \mathrm{~h}$ and 18:6 h, using discontinuous artificial illumination provided by $12 \mathrm{~V} / 24 \mathrm{~W}$ white LED lamps under an irradiance value of $108 \mu \mathrm{mol} \cdot \mathrm{photon} \cdot \mathrm{m}^{-2} \cdot \mathrm{s}^{-1}$.

Each species was cultivated in two different synthetic nutrient media: Guillard's F/2 (EasyAlgae. Cádiz, Spain) and Walne's (Aqualgae. A Coruña, Spain), both in fresh and seawater. Synthetic seawater was produced with CoralMarine EasyMix (GroTech GmbH. Langenhansen, Germany) according to manufacturer's instructions, to a final concentration of $33.3 \mathrm{~g} / \mathrm{L}$. Microalgae were also cultivated in waters withdrawn from different stages of Rey Juan Carlos University waste water treatment plant located in its Campus in Mostoles (Madrid, Spain). Table 1 shows the identification of each cultivation media and the composition of media and wastewaters is shown in Tables S1 and S6, respectively.

The microalgae and cyanobacteria were allowed to grow for two weeks at $25^{\circ} \mathrm{C}$. The optical density of the culture was measured using a V-630 spectrophotometer (Jasco Analítica Spain, Madrid, Spain) at $540 \mathrm{~nm}$. To determine the dry weight content, a calibration with biomass from the stationary phase was performed to establish the absorbance-dry weight relationship. For this purpose, a homogeneous sample of the culture was centrifuged at $5000 \mathrm{rpm}$ for $5 \mathrm{~min}$ and then the solid phase containing biomass was dried at $105{ }^{\circ} \mathrm{C}$ overnight and allowed to cool down to room temperature inside a desiccator to obtain the weight of dry microalgae. The $\mathrm{pH}$ was measured every day with a Basic $30 \mathrm{pH}$ meter (Crison Instruments. Barcelona, Spain).

Once the culture conditions had been optimised in the mini-photobioreactors, the process was scaled to a $12 \mathrm{~L}$ photobioreactor to fully characterise the microalgal biomass as a function of time and state of growth of the microalgae. A modified Bioflo 110 (New Brunswick Scientific, Edison, NJ, USA) bioreactor/fermenter, adapted for the culture of photosynthetic microorganisms, was used as a photobioreactor system. An in-house designed $12 \mathrm{~L}$ jacketed glass vessel was employed, in which $\mathrm{pH}$, temperature and stirring were controlled automatically. The culture vessel was placed inside a metal housing fitted with $8 \mathrm{~W}$ Sylvania fluorescent lights, which allow controlling the lighting inside the reactor during the chosen light photoperiod. Aeration of the reactor was carried out by a membrane pump at a flow rate of $1.75 \mathrm{~L} / \mathrm{h}$, providing the necessary $\mathrm{CO}_{2}$ amount as carbon source.

\subsection{Analysis of Biomass}

Every day, $0.5 \mathrm{~L}$ of culture was withdrawn, centrifuged and vacuum-dried to obtain the biomass for further analysis. Dry microalga cells $(0.5 \mathrm{~g})$ were lysed with $5 \mathrm{~mL}$ lysis buffer (aqueous solution containing $1.1 \mathrm{mM}$ ethylenedinitrilotetraacetic acid disodium salt, $0.2 \mathrm{mM}$ phenylmethylsulfonyl fluoride and $0.5 \%$ Triton-X100) under vortex stirring for $5 \mathrm{~min}$. Protein concentration was measured by Bradford's method [61] using Quick-Start ${ }^{\circledR}$ Protein Assay Kit (Bio-Rad Laboratories. Hercules, CA, USA) according to manufacturer's instructions. The method is based on the shift of the wavelength of maximum absorbance of the dye reagent Coomassie ${ }^{\circledR}$ Brilliant Blue G-250 from $465 \mathrm{~nm}$ to $595 \mathrm{~nm}$ when it is bonded to a protein. The quantification of protein concentration was performed by measuring the absorbance at $595 \mathrm{~nm}$ in a V-630 spectrophotometer (Jasco Analítica. Madrid, Spain) using bovine serum albumin as standard protein to build the calibration curve assuming Lambert-Beer law is followed.

The carbohydrate content was measured by the DuBois method [62] using glucose as calibration standard. The carbohydrate soluble fraction was measured from lysed cells suspension using a DNS solution (1 $\mathrm{g}$ of 3,5-dinitrosalicylic acid, $30 \mathrm{~g}$ of sodium potassium tartrate tetrahydrate, $50 \mathrm{~mL}$ of water and $20 \mathrm{~mL} 2 \mathrm{~N} \mathrm{NaOH}$ ). The procedure was as follows: $1 \mathrm{~mL}$ of each sample and each calibration solution was placed in a test tube. Then, $1 \mathrm{~mL}$ of DNS was added, and the resulting solution was 
vortexed, heated in a water bath at $100{ }^{\circ} \mathrm{C}$ for $10 \mathrm{~min}$ and cooled by quenching in ice. Finally, $10 \mathrm{~mL}$ of distilled water were added, and the solution was measured with a V-630 spectrophotometer at $540 \mathrm{~nm}$.

Elemental analysis was performed in a Vario EL III CHNS (Elementar Analysensysteme GmbH. Langenselbold, Germany) to quantify the amount of carbon, hydrogen, nitrogen, and sulfur in the microalgae and the oxygen amount was calculated by mass balance. Around $10 \mathrm{mg}$ of dry weight were weighted and fully oxidised in an air stream at $1000{ }^{\circ} \mathrm{C}$. Then, the oxidation products were transported by a carrier gas (helium) through selective adsorption columns. The gases were then measured with a thermal conductivity detector. Sulfanilic acid was used as standard for element quantification.

The lipids were extracted using a chloroform:methanol $(4 / 5 v / v)$ solvent mixture and the lipid concentration was calculated gravimetrically [63]. Nitrate content was measured using a $781 \mathrm{pH} / \mathrm{Ion}$ meter equipped with a polymer-membrane selective electrode (Metrohm. Herisau, Switzerland). For the quantification, a standard calibration curve with sodium nitrate was prepared.

The metal content in the microalgal biomass and in the solution of the cultivation media was monitored by induced plasma atomic emission spectroscopy (ICP-AES) on a Vista AXCCD simultaneous ICP-AES (Varian. Palo Alto, CA, USA). Dry microalgae biomass $(0.1 \mathrm{~g})$ were treated by acid digestion with $2 \mathrm{~mL}$ of $98 \%$ sulfuric acid and $10 \mathrm{~mL}$ of deionised water. The sample was heated to dryness. The resulting solid was calcined at $750{ }^{\circ} \mathrm{C}$ (heating at $50{ }^{\circ} \mathrm{C} / \mathrm{min}$ ) for $5 \mathrm{~h}$. The resulting ash was digested with $2 \mathrm{~mL}$ of $98 \%$ sulfuric acid and $10 \mathrm{~mL}$ of $48 \%$ hydrofluoric acid and heating until complete evaporation of hydrofluoric acid. Then, the liquid sample was diluted with deionised water up to 50 $\mathrm{mL}$ for analysis. Filtration through a $0.45 \mu \mathrm{m}$ nylon membrane was the only preparation treatment for the samples of aqueous cultivation media.

All analysis were performed in triplicate to allow calculation of average values and standard errors of each measurement.

\subsection{Growth Kinetics}

Biomass growth and nutrient removal was monitored as described above and that information was used to model the specific growth rate $(\mu)$ following a first-order kinetics (Equation (1)) assuming a Monod-type kinetics with nitrate as limiting nutrient (Equation (2)).

$$
\begin{gathered}
\mu=\frac{1}{X} \frac{d X}{d t} \\
\mu=\mu_{\max } \frac{S}{K_{S}+S}
\end{gathered}
$$

where $X$ is the biomass concentration in dry basis $(\mathrm{g} / \mathrm{L}), S$ the nitrate concentration $(\mathrm{mg} / \mathrm{L}), \mu_{\max }$ the maximum specific growth rate $\left(\mathrm{d}^{-1}\right)$ and $K_{S}$ the half-saturation constant $(\mathrm{mg} / \mathrm{L})$. Therefore, the kinetic parameters $\mu$ max and $K_{S}$ can be calculated from the monitoring of growth and nitrate consumption with time during the exponential phase, assuming that the specific growth rate is constant during this phase. Growth and nitrate uptake are also related through the corresponding yield coefficient $\left(Y_{X / S}\right.$, Equation (3)) which gives the amount of biomass produced by unit mass of nitrate consumed by the microorganism.

$$
Y_{X / S}=-\frac{\Delta X}{\Delta S}
$$

\subsection{Statistical Analysis}

Numerical experimental results are shown as the mean value of three replicates \pm standard deviation. One-way Analysis of Variance (ANOVA) was performed using Statgraphics Centurion XVII (StatPoint Technologies, Inc. Warrenton, VA, USA) to assess the statistical significance of the means between different treatments. The criteria to consider statistical significance between different means was $p$-value $<0.05$. 


\section{Conclusions}

The effect of cultivation variables on the growth of three microalgae and one cyanobacterium with potential industrial interest was evaluated. Whereas the initial inoculum volume did not affect the final biomass production, the amount of light to which the microalgae were exposed was a significant factor. Thus, the photoperiod 12:12 $\mathrm{h}$ light:dark was the most favourable for the growth of the four species. The analysis of biomass composition showed that for A. maxima and I. galbana, the protein content increased during the exponential phase while for N. gaditana and C. vulgaris, the accumulation of proteins ended before the stationary phase was reached. Nitrate and iron, as macro- and micro-nutrients respectively, became the limiting compounds for all four species, with copper being essential for growth in marine media. Although all of the species studied were able to grow in wastewaters, I. galbana, N. gaditana and C. vulgaris achieved higher nitrogen removal capacity than cyanobacterium A. maxima.

Supplementary Materials: The following are available online, Table S1. Composition of Guillard's F/2 and Walne's media, Table S2: Elemental composition (\%) of $A$. maxima at different times, Table S3: Elemental composition (\%) of C. vulgaris at different times, Table S4: Elemental composition (\%) of I. galbana at different times, Table S5: Elemental composition (\%) of N. gaditana at different times, Table S6: Characterisation of water samples from wastewater treatment plant located at Campus of Móstoles (Universidad Rey Juan Carlos), Table S7: Phosphorus depletion in wastewater AD2, Figure S1: Nitrate uptake in wastewater AD2.

Author Contributions: L.F.B. and G.V. devised the experimental work, analysed the tests and wrote the final version of the manuscript. A.S.-B. performed the experimental work, sample characterisation and made a first draft of the manuscript. V.M. and R.R. analysed and discussed the results. The listed authors have contributed substantially to this work. All authors have read and agreed to the published version of the manuscript.

Funding: The authors acknowledge the support from INSPIRA1 (S2013/ABI-2783) and ALGATEC-CM (S2018/BAA-4532) projects, both financed by Comunidad de Madrid and co-financed by the European Social Fund and the European Regional Development Fund and RENUWAL network (320RT0005) financed by the CYTED Program.

Conflicts of Interest: The authors declare no conflict of interest.

\section{References}

1. Guiry, M.D. How many species of algae are there? J. Phycol. 2012, 48, 1057-1063. [CrossRef]

2. Carrieri, D.; Ananyev, G.; Brown, T.; Dismukes, G.C. In vivo bicarbonate requirement for water oxidation by Photosystem II in the hypercarbonate-requiring cyanobacterium Arthrospira maxima. J. Inorg. Biochem. 2007, 101, 1865-1874. [CrossRef] [PubMed]

3. Gutiérrez-Rebolledo, G.A.; Galar-Martínez, M.; García-Rodríguez, R.V.; Chamorro-Cevallos, G.A.; Hernández-Reyes, A.G.; Martínez-Galero, E. Antioxidant effect of Spirulina (Arthrospira) maxima on chronic inflammation induced by Freund's complete adjuvant in rats. J. Med. Food 2015, 18, 865-871. [CrossRef] [PubMed]

4. Salati, S.; D’Imporzano, G.; Menin, B.; Veronesi, D.; Scaglia, B.; Abbruscato, P.; Mariani, P.; Adani, F. Mixotrophic cultivation of Chlorella for local protein production using agro-food by-products. Bioresour. Technol. 2017, 230, 82-89. [CrossRef] [PubMed]

5. Fawley, K.P.; Fawley, M.W. Observations on the diversity and ecology of freshwater Nannochloropsis (Eustigmatophyceae), with descriptions of new taxa. Protist 2007, 158, 325-336. [CrossRef]

6. Scholz, M.J.; Weiss, T.L.; Jinkerson, R.E.; Jing, J.; Roth, R.; Goodenough, U.; Posewitz, M.C.; Gerken, H.G. Ultrastructure and composition of the Nannochloropsis gaditana cell wall. Eukaryot. Cell 2014, 13, 1450-1464. [CrossRef]

7. Mendoza, A.; Vicente, G.; Bautista, L.F.; Morales, V. Opportunities for biomass through the isolation of its components and biodiesel production. Green Process. Synth. 2015, 4, 97-102.

8. Sánchez, Á.; Maceiras, R.; Cancela, Á.; Pérez, A. Culture aspects of Isochrysis galbana for biodiesel production. Appl. Energy 2013, 101, 192-197. [CrossRef]

9. Bautista, L.F.; Vicente, G.; Mendoza, A.; González, S.; Morales, V. Enzymatic production of biodiesel from Nannochloropsis gaditana microalgae using immobilized lipases in mesoporous materials. Energy Fuels 2015, 29, 4981-4989. [CrossRef] 
10. Park, C.; Lee, J.H.; Yang, X.; Yoo, H.Y.; Lee, J.H.; Lee, S.K.; Kim, S.W. Enhancement of hydrolysis of Chlorella vulgaris by hydrochloric acid. Bioprocess Biosyst. Eng. 2016, 39, 1015-1021. [CrossRef]

11. Mendez, L.; Sialve, B.; Tomás-Pejó, E.; Ballesteros, M.; Steyer, J.P.; González-Fernández, C. Comparison of Chlorella vulgaris and cyanobacterial biomass: Cultivation in urban wastewater and methane production. Bioprocess Biosyst. Eng. 2016, 39, 703-712. [CrossRef] [PubMed]

12. Khetkorn, W.; Rastogi, R.P.; Incharoensakdi, A.; Lindblad, P.; Madamwar, D.; Pandey, A.; Larroche, C. Microalgal hydrogen production-A review. Bioresour. Technol. 2017, 243, 1194-1206. [CrossRef] [PubMed]

13. Harun, R.; Singh, M.; Forde, G.M.; Danquah, M.K. Bioprocess engineering of microalgae to produce a variety of consumer products. Renew. Sustain. Energy Rev. 2010, 14, 1037-1047. [CrossRef]

14. Jorquera, O.; Kiperstok, A.; Sales, E.A.; Embiruçu, M.; Ghirardi, M.L. Comparative energy life-cycle analyses of microalgal biomass production in open ponds and photobioreactors. Bioresour. Technol. 2010, 101, 1406-1413. [CrossRef] [PubMed]

15. Allen, J.F. Botany: State transitions-A question of balance. Science (80) 2003, 299, 1530-1532. [CrossRef]

16. Camacho-Rodríguez,J.; Cerón-García,M.C.; González-López,C.V.; Fernández-Sevilla, J.M.; Contreras-Gómez, A.; Molina-Grima, E. A low-cost culture medium for the production of Nannochloropsis gaditana biomass optimized for aquaculture. Bioresour. Technol. 2013, 144, 57-66. [CrossRef]

17. Picardo, M.C.; De Medeiros, J.L.; Ofélia de Queiroz, F.A.; Chaloub, R.M. Effects of $\mathrm{CO}_{2}$ enrichment and nutrients supply intermittency on batch cultures of Isochrysis galbana. Bioresour. Technol. 2013, 143, 242-250. [CrossRef]

18. Walne, P.R. Studies on the Food Value of Nineteen Genera of Algae to Juvenile Bivalves of the Genera Ostrea, Crassostrea, Mercenaria and Mytilus; Fishery Investigations; H.M. Stationery Office: London, UK, 1970; Volume 26, ISBN 9780112406211.

19. Guillard, R.R.; Ryther, J.H. Ryther Studies on marine planktonic diatoms I. Cyclotella nana Hustedt and Detonula confervacea (Cleve). Can. J. Microbiol. 1962, 8, 229-239.

20. Hwang, J.-H.; Church, J.; Lee, S.-J.; Park, J.; Lee, W.H. Use of microalgae for advanced wastewater treatment and sustainable bioenergy generation. Environ. Eng. Sci. 2016, 33, 882-897. [CrossRef]

21. Lee, E.; Jalalizadeh, M.; Zhang, Q. Growth kinetic models for microalgae cultivation: A review. Algal Res. 2015, 12, 497-512. [CrossRef]

22. Georgianna, D.R.; Mayfield, S.P. Exploiting diversity and synthetic biology for the production of algal biofuels. Nature 2012, 488, 329-335. [CrossRef]

23. Gonçalves, A.L.; Pires, J.C.M.; Simões, M. The effects of light and temperature on microalgal growth and nutrient removal: An experimental and mathematical approach. RSC Adv. 2016, 6, 22896-22907. [CrossRef]

24. Vanags, J.; Kunga, L.; Dubencovs, K.; Galvanauskas, V.; Grīgs, O. Influence of light intensity and temperature on cultivation of microalgae Desmodesmus communis in flasks and laboratory-scale stirred tank photobioreactor. Latv. J. Phys. Tech. Sci. 2015, 52, 59-70. [CrossRef]

25. Jacob-Lopes, E.; Scoparo, C.H.G.; Lacerda, L.M.C.F.; Franco, T.T. Effect of light cycles (night/day) on $\mathrm{CO}_{2}$ fixation and biomass production by microalgae in photobioreactors. Chem. Eng. Process. Process Intensif. 2009, 48, 306-310. [CrossRef]

26. Fábregas, J.; Maseda, A.; Domínguez, A.; Ferreira, M.; Otero, A. Changes in the cell composition of the marine microalga, Nannochloropsis gaditana, during a light:dark cycle. Biotechnol. Lett. 2002, 24, 1699-1703. [CrossRef]

27. Simionato, D.; Sforza, E.; Corteggiani Carpinelli, E.; Bertucco, A.; Giacometti, G.M.; Morosinotto, T. Acclimation of Nannochloropsis gaditana to different illumination regimes: Effects on lipids accumulation. Bioresour. Technol. 2011, 102, 6026-6032. [CrossRef]

28. Paes, C.R.P.S.; Faria, G.R.; Tinoco, N.A.B.; Castro, D.J.F.A.; Barbarino, E.; Lourenco, S.O. Growth, nutrient uptake and chemical composition of Chlorella sp. and Nannochloropsis oculata under nitrogen starvation. Lat. Am. J. Aquat. Res. 2016, 44, 275-292. [CrossRef]

29. Whitton, R.; Le Mével, A.; Pidou, M.; Ometto, F.; Villa, R.; Jefferson, B. Influence of microalgal N and P composition on wastewater nutrient remediation. Water Res. 2016, 91, 371-378. [CrossRef]

30. Orefice, I.; Musella, M.; Smerilli, A.; Sansone, C.; Chandrasekaran, R.; Corato, F.; Brunet, C. Role of nutrient concentrations and water movement on diatom's productivity in culture. Sci. Rep. 2019, 9, 1479. [CrossRef] 
31. Li, X.; Hu, H.-Y.; Gan, K.; Sun, Y.-X. Effects of different nitrogen and phosphorus concentrations on the growth, nutrient uptake, and lipid accumulation of a freshwater microalga Scenedesmus sp. Bioresour. Technol. 2010, 101, 5494-5500.

32. Ravelonandro, P.H.; Ratianarivo, D.H.; Joannis-Cassan, C.; Isambert, A.; Raherimandimby, M. Improvement of the growth of Arthrospira (Spirulina) platensis from Toliara (Madagascar): Effect of agitation, salinity and $\mathrm{CO}_{2}$ addition. Food Bioprod. Process. 2011, 89, 209-216. [CrossRef]

33. Shi, W.; Li, S.; Li, G.; Wang, W.; Chen, Q.; Li, Y.; Ling, X. Investigation of main factors affecting the growth rate of Spirulina. Opt. Int. J. Light Electron Opt. 2016, 127, 6688-6694. [CrossRef]

34. May, W.A. Effects of temperature and $\{\mathrm{pH}\}$ on the growth kinetics of unialga Chlorella vulgaris cultures containing bacteria. Water Environ. Res. 1997, 69, 64-72. [CrossRef]

35. Xueqin, W.; Pei, Z.; Ping, H.; Lili, P.; Lei, H.; Chu, C.; Linglin, L.; Rong, Z. Optimization of cultural conditions of Isochrysis galbana Parks 3011 and its mass-cultural. Food Sci. 2006, 27, 253-258.

36. Bartley, M.L.; Boeing, W.J.; Dungan, B.N.; Holguin, F.O.; Schaub, T. pH effects on growth and lipid accumulation of the biofuel microalgae Nannochloropsis salina and invading organisms. J. Appl. Phycol. 2014, 26, 1431-1437. [CrossRef]

37. Lin, Y.H.; Chang, F.L.; Tsao, C.Y.; Leu, J.Y. Influence of growth phase and nutrient source on fatty acid composition of Isochrysis galbana CCMP 1324 in a batch photoreactor. Biochem. Eng. J. 2007, 37, 166-176. [CrossRef]

38. Rocha, J.M.S.; Garcia, J.E.C.; Henriques, M.H.F. Growth aspects of the marine microalga. Biomol. Eng. 2003, 20, 237-242. [CrossRef]

39. Dos Santos, R.R.; Araújo, O.D.Q.F.; De Medeiros, J.L.; Chaloub, R.M. Cultivation of Spirulina maxima in medium supplemented with sugarcane vinasse. Bioresour. Technol. 2016, 204, 38-48. [CrossRef]

40. Valenzuela-Espinoza, E.; Millán-Núñez, R.; Núñez-Cebrero, F.; Valenzuela-Espinoza, E.; Millan-Nunez, R.; Nunez-Cebrero, F. Protein, carbohydrate, lipid and chlorophyll a content in Isochrysis aff. galbana (clone T-Iso) cultured with a low cost alternative to the f/2 medium. Aquac. Eng. 2002, 25, 207-216.

41. Colla, L.M.; Oliveira Reinehr, C.; Reichert, C.; Costa, J.A.V. Production of biomass and nutraceutical compounds by Spirulina platensis under different temperature and nitrogen regimes. Bioresour. Technol. 2007, 98, 1489-1493. [CrossRef]

42. Sassano, C.E.N.; Gioielli, L.A.; Ferreira, L.S.; Rodrigues, M.S.; Sato, S.; Converti, A.; Carvalho, J.C.M. Evaluation of the composition of continuously-cultivated Arthrospira (Spirulina) platensis using ammonium chloride as nitrogen source. Biomass Bioenergy 2010, 34, 1732-1738. [CrossRef]

43. Zarrouk, C. Contribution a l'etude d'une Cyanobacterie: Influence de divers facteurs physiques et chimiques sur la croissance et la photosynthese de Spirulina maxima (Setchell et Gardner) Geitler. Ph.D. Thesis, University of Paris, Paris, France, 1966.

44. Walach, M.R.; Bazin, M.J.; Pirt, S.J.; Balyuzi, H.H.M. Computer control of carbon-nitrogen ratio in Spirulina platensis. Biotechnol. Bioeng. 1987, 29, 520-528. [CrossRef] [PubMed]

45. Postma, P.R.; Suarez Garcia, E.; Safi, C.; Yonathan, K.; Olivieri, G.; Barbosa, M.J.; Wijffels, R.H.; Eppink, M.H.M. Energy efficient bead milling of microalgae: Effect of bead size on disintegration and release of proteins and carbohydrates. Bioresour. Technol. 2017, 224, 670-679. [CrossRef] [PubMed]

46. Gim, G.H.; Ryu, J.; Kim, M.J.; Kim, P.I.; Kim, S.W. Effects of carbon source and light intensity on the growth and total lipid production of three microalgae under different culture conditions. J. Ind. Microbiol. Biotechnol. 2016, 43, 605-616. [CrossRef]

47. Halim, R.; Danquah, M.K.; Webley, P.A. Extraction of oil from microalgae for biodiesel production: A review. Biotechnol. Adv. 2012, 30, 709-732. [CrossRef]

48. $\mathrm{Xu}, \mathrm{Y}$; Boeing, W.J. Modeling maximum lipid productivity of microalgae: Review and next step. Renew. Sustain. Energy Rev. 2014, 32, 29-39. [CrossRef]

49. Tanikawa, D.; Yamashita, S.; Kataoka, T.; Sonaka, H.; Hirakata, Y.; Hatamoto, M.; Yamaguchi, T. Non-aerated single-stage nitrogen removal using a down-flow hanging sponge reactor as post-treatment for nitrogen-rich wastewater treatment. Chemosphere 2019, 233, 645-651. [CrossRef]

50. Chen, S.-Y.; Pan, L.-Y.; Hong, M.-J.; Lee, A.-C. The effects of temperature on the growth of and ammonia uptake by marine microalgae. Bot. Stud. 2012, 53, 125-133.

51. Nakamura, H.; Shiozaki, T.; Gonda, N.; Furuya, K.; Matsunaga, S.; Okada, S. Utilization of ammonium by the hydrocarbon-producing microalga, Botryococcus braunii Showa. Algal Res. 2017, 25, 445-451. [CrossRef] 
52. González-Camejo, J.; Aparicio, S.; Ruano, M.V.; Borrás, L.; Barat, R.; Ferrer, J. Effect of ambient temperature variations on an indigenous microalgae-nitrifying bacteria culture dominated by Chlorella. Bioresour. Technol. 2019, 290, 121788. [CrossRef]

53. Ji, M.K.; Abou-Shanab, R.A.; Hwang, J.H.; Timmes, T.C.; Kim, H.C.; Oh, Y.K.; Jeon, B.H. Removal of nitrogen and phosphorus from piggery wastewater effluent using the green microalga Scenedesmus obliquus. J. Environ. Eng. 2013, 139, 1198-1205. [CrossRef]

54. Wuang, S.C.; Khin, M.C.; Chua, P.Q.D.; Luo, Y.D. Use of Spirulina biomass produced from treatment of aquaculture wastewater as agricultural fertilizers. Algal Res. 2016, 15, 59-64. [CrossRef]

55. Arora, N.; Patel, A.; Pruthi, P.A.; Poluri, K.M.; Pruthi, V. Utilization of stagnant non-potable pond water for cultivating oleaginous microalga for biodiesel production. Renew. Energy 2018, 126, 30-37. [CrossRef]

56. Raeesossadati, M.J.J.; Ahmadzadeh, H.; McHenry, M.P.P.; Moheimani, N.R.R. $\mathrm{CO}_{2}$ bioremediation by microalgae in photobioreactors: Impacts of biomass and $\mathrm{CO}_{2}$ concentrations, light, and temperature. Algal Res. 2014, 6, 78-85. [CrossRef]

57. Novoveská, L.; Zapata, A.K.M.; Zabolotney, J.B.; Atwood, M.C.; Sundstrom, E.R. Optimizing microalgae cultivation and wastewater treatment in large-scale offshore photobioreactors. Algal Res. 2016, 18, 86-94. [CrossRef]

58. Lam, M.K.; Yusoff, M.I.; Uemura, Y.; Lim, J.W.; Khoo, C.G.; Lee, K.T.; Ong, H.C. Cultivation of Chlorella vulgaris using nutrients source from domestic wastewater for biodiesel production: Growth condition and kinetic studies. Renew. Energy 2017, 103, 197-207. [CrossRef]

59. Kaplan, D.; Cohen, Z.; Abeliovich, A. Optimal growth conditions for lsochrysis galbana. Biomass 1986, 9, 37-48. [CrossRef]

60. Luangpipat, T.; Chisti, Y. Biomass and oil production by Chlorella vulgaris and four other microalgae-Effects of salinity and other factors. J. Biotechnol. 2016, 257, 47-57. [CrossRef]

61. Bradford, M.M. A rapid and sensitive method for the quantitation of microgram quantities of protein utilizing the principle of protein-dye binding. Anal. Biochem. 1976, 72, 248-254. [CrossRef]

62. DuBois, M.; Gilles, K.A.; Hamilton, J.K.; Rebers, P.A.; Smith, F. Colorimetric method for determination of sugars and related substances. Anal. Chem. 1956, 28, 350-356. [CrossRef]

63. Breuer, G.; Evers, W.A.C.; De Vree, J.H.; Kleinegris, D.M.M.; Martens, D.E.; Wijffels, R.H.; Lamers, P.P. Analysis of fatty acid content and composition in microalgae. J. Vis. Exp. 2013, 1, e50628. [CrossRef] [PubMed]

Sample Availability: Samples of the compounds are not available from the authors.

(C) 2020 by the authors. Licensee MDPI, Basel, Switzerland. This article is an open access article distributed under the terms and conditions of the Creative Commons Attribution (CC BY) license (http://creativecommons.org/licenses/by/4.0/). 